\title{
"LAS HOJAS DEL CIPRES" CLAUSURA DEL PROYECTO LITERARIO DE JORGE LUIS BORGES
}

\author{
Oscar Montanaro Meza*
}

\begin{abstract}
In the following article I analyze the story "Las hojas del ciprés" included in Los conjurados, the last book published by Jorge Luis Borges. I conclude that the essential elements of the literary production of Borges are maintained in the this text, as shown by the fact that the narrator provides the keys to the genesis of the story, just as occurs in the narrative texts included in La histbria universal de la infamia.
\end{abstract}

\section{INTRODUCCION}

La producción narrativa de Jorge Luis Borges abarcó, de acuerdo con las ediciones de sus libros, cincuenta años que se extienden de 1935 -con la primera edición de Historia universal de la infamiahasta 1985 -con la publicación de Los conjurados (1), obra en la cual, además de poemas, incluye varios microrrelatos. De ellos, se ha scleccionado uno: "Las hojas del ciprés", con el propósito de analizar en ese texto las claves de la narrativa de Borges que aparecen a través de sus relatos y que, por tal razón, permite considerar ese texto como una clausura del quehacer cuentístico del autor argentino.

El dinámico rol del lector frente al "scripteur", la violencia, el texto literario concebido como espejo y laberinto, la ausencia de crítica social, son rasgos propios del texto borgense. Tras esta elaboración mesurada de la obra, hay lo que denomina Macherey un "desorden real determinado", ya que, como él afirma, el orden que se da en la obra

“...n' est qu' un ordre imaginé, projeté là ou il n' y a pas d' ordre, et qui sert à resourdre fictivement les conflits idéologiques" (2).

El productor resuelve esta situación conflictiva con juegos filosóficos y verbales, según ha sido expuesto en esta tesis; también Borges, extratextualmente, confirma la indagación textual realizada, cuando afirma:

\footnotetext{
* Profesor Asociado de la Universidad de Costa Rica. Sede de
} Occidente.

\begin{abstract}
"...lo que puede ser un lugar común filosífico, puede ser una novedad en lo narrativo" (3).
\end{abstract}

Más adelante, al referirse en esa entrevista al cuento tan celebrado por la crítica "Tlöon, Uqbar, Orbis Tertius", expresa una clave constante de su narrativa consistente en la incorporación de obras, autores y lugares "reales" en el texto de ficción; véase la cita:

“...puse muchos nombres de personas reales, ahí, yo estaba jugando,... (4).

La verdad que el juego ni empezó, ni acabó en este importante cuento: el comenzó con Historia universal de la infamia y continuó presente en la narrativa de Borges hasta llegar al microrrelato "Las hojas del ciprés".

De ahí que el libro antes referido ha sido considerado en esta investigación como el "incipit" de la producción narrativa del escritor argentino.

En el marco de las observaciones anteriores se analizará el texto "Las hojas del ciprés".

\section{EL TEXTO PREFACIAL}

En esta obra reitera Borges su costumbre de escribir un "hors-texte"; manifiesta en el prólogo sus apreciaciones sobre el quehacer literario y en particular, sobre el libro que lo ocupa. También hay una dedicatoria, denominada aquí "Inscripción", y en la cual, además de ofrecerle la obra a María Kodama, reflexiona breve y sentenciosamente sobre el lenguaje. 
Cabe apuntar que en el "prólogo" refiere Borges la génesis de su producción textual:

"En este libro hay muchos sueños. Aclaro que fueron dones de la noche, más precisamente, del alba no ficciones deliberadas". (5).

Muestra el autor en esa cita una importante clave de su trabajo literario: advierte al lector que su texto es producto de los "sueños" y "no ficciones deliberadas", es decir, una vez más, Borges se aleja de la literatura concebida como creación ex nihilo.

\section{LA DIEGESIS}

Ahora bien, la diégesis del texto "Las hojas del ciprés" se estructura con base en los sueños que afectan al protagonista durante el transcurso de una noche.

Inicia su historia señalando que tiene "un solo enemigo", quien sin saber de qué manera

“...pudo entrar en mi casa, la noche del 14 de abril de 1977"

Luego de abrir dos puertas: la de la calle y la del apartamento, narra que:

"Prendió la luz y me despertó de una pesadilla que no recuerdo, pero en la que había un jardín" (7).

A partir de este despertar se inicia la acción. El "enemigo" lo saca de su departamento porque el sitio destinado a la ejecución quedaba un poco lejos. En un "cupé" inicia el viaje "lento" y "silencioso". El viaje concluye. El y su captor suben unas gradas de piedra a un sitio en que hay "canteras" y "árboles". El "enemigo" le ordena tenderse en el pasto de espaldas y en cruz, al pie de un árbol. En el momento en que vio "el fulgor del acero" despierta. Extrañado de esta segunda "pesadilla" vuelve a hundirse en el sueño. Al otro día, cuando despierta se da cuenta de que en su biblioteca falta el tomo de las obras de Emerson que, en el sueño, se había llevado. Diez días después sabe que su "enemigo" había salido una noche de casa y que desde entonces no ha regresado. Y al respecto, clausurando su relato, narra el protagonista:

"Nunca regresará. Encerrado en mi pesadilla, seguirá descubriendo con horror, bajo la luna que no vi, la ciudad de relojes en blanco, de árboles falsos que no pueden crecer y nadie sabe que otras cosas" (8).

El sueño pasa a través de la realidad (el tomo de Emerson y el "enemigo") y ambos llegan a igualarse, porque el libro se quedó en el sueño, el "enemigo" se pierde en él y el ciprés sale del sueño a la realidad como prueba de la pesadilla. En consecuencia, el narrador ha identificado la realidad y el sueño, tal y como se esboza en el diagrama de la página 9.

\section{ALGUNAS OBSERVACIONES TITULOLOGICAS}

Mientras el título del texto "Las hojas del ciprés" posee una significación neutra, en cambio, el del libro Los conjurados alude a una constante de la historia de la República Argentina: las conjuraciones incitadas por los militares. Sin embargo, el operador actancial de este título corresponde en el relato homólogo y que cierra el libro, a un espacio europeo: Suiza, y a un tiempo lejano: el siglo quince. Ahora bien, si el relato "Las hojas del ciprés" toca el tema de los secuestros y la violencia que los provoca, su título refiere a un operador objetal, que al explicitarse en el contex to se constituye en otro elemento más para enfatizar que lo sucedido esa noche fue una pesadilla, porque según la descripción el árbol de ciprés es un objeto estático, rígido, sin vida y destinado a una función de muerte que no cumple gracias a que la víctima despierta. La ambigüedad de los títulos indicados es evidente: el primero, si toca un problema político actual, su contexto lo aleja espacial y temporalmente; y el segundo, si se refiere a un objeto inocente, desarrolla su contexto la pesadilla de un secuentro nocturno, en el cual la realidad se identifica con la pesadilla y por consiguiente ésta con aquélla.

\section{EL ROL DEL "LECTEUR"}

En "Las hojas del ciprés" la función del "lecteur" adquiere relevancia porque es él quien determina si la cadena de sueños se interrumpe, o si ella continuará. Recuérdese que al sintetizar la diégesis se destacó el momento en que el "enemigo" prendió la luz del cuarto y lo despertó de una pesadilla en la que había "un jardín". Luego de lo acontecido sabe el lector que todo ocurrió en un sueño.

"Me desperté; mi mano izquierda tocaba la pared de mi cuarto".

Al llegar a este punto, la lectura puede tomar dos caminos: aceptar que las pesadillas continúan, o 
bien, que ellas han concluido. El "scripteur" no presenta una respuesta categórica, sino una idea ambigua.
"Qué pesadilla rara, pensé, y no tardé en hundirme en el sueño".

"Las hojas del ciprés": diagrama diegético

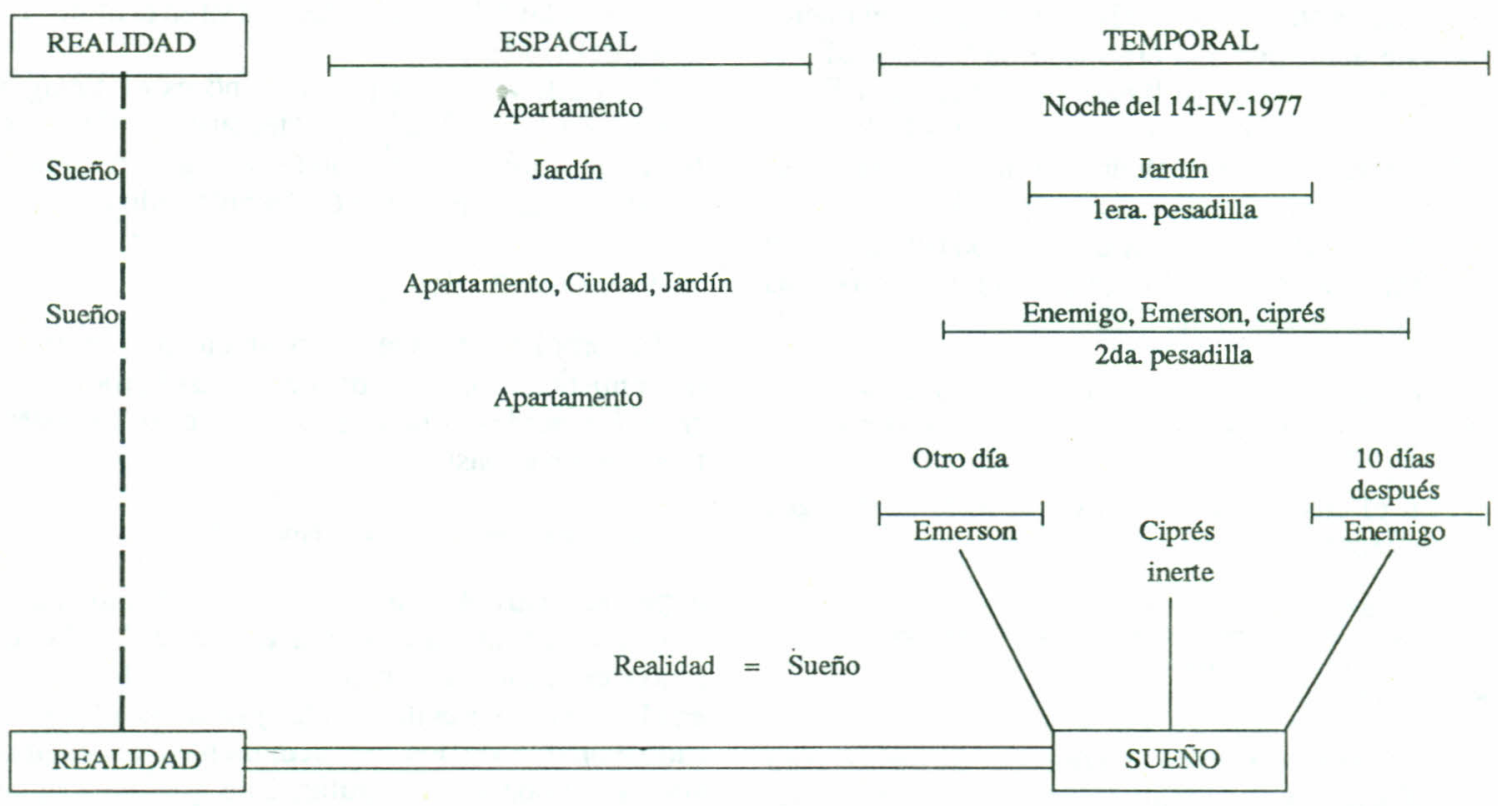

El párrafo que sigue a la cita última se inicia así:

"Al día siguiente descubrí que en el anaquel había un hueco..." (9).

Ello puede ser interpretado el inicio de una nueva pesadilla dentro de la otra, según el principio de las "muñecas rusas" llevado al infinito; pero también, puede interpretarse que el mundo onírico cede su lugar a la vigilia cotidiana. Se repite pues, en este texto, la presencia de una lectura abierta, que coloca al "Lecteur" en el ámbito de una incertidumbre irónica: será posible que un "sueño" derrote al "enemigo". Es tan horrible el secuestro nocturno que es visto como una pesadilla de la cual el narrador no sabe cómo despertar. Borges, al emplear la ironía, acude a otro recurso más para elevar la posición del lector, ya que

“...la ironía exige al receptor tomar una parte activa suplementaria (debe hacer la descodificación del discurso, además de la lingüística) en la construcción de la significación, dándole el estatus de verdadero interlocutor..." (10).
Una vez más, equipara la importancia del trabajo escritural con el acto de la lectura.

\section{LOS INTERTEXTOS}

El tema de este texto aparece ya en un microrrelato titulado "Episodio del enemigo"; en su diégesis el protagonista "Borges" se enfrenta contra su "enemigo" y mantienen un diálogo que concluye así:

“...Usted ya no puede hacer nada.

- Puedo hacer una cosa- le contesté.

- ¿Cuál?-me preguntó.

- Despertarme.

Y asílo hice" (11).

Con el hecho de despertar implícitamente el enemigo es derrotado en el sueño, tal como ocurre en "Las hojas del ciprés".

También la intertextualidad restringida se da con el cuento "El Sur" según los ejemplos siguientes: 
a) "El gato Beppo nos miraba desde su eternidad" (12)

b) "Pensé: ya estamos en el Sur" (14). “...el mágico animal (un gato) vive, en la actualidad, en la eternidad del instante" (13).

"...Dahlmann pudo sospechar que viajaba al pasado y no sólo al Sur" (15).
Lapresencia del "Sur" en ambos relatos, así como en muchos otros textos de Borges, muestra el interés de este autor por una búsqueda de "identidad", la cual, precisamente se busca en la dirección Sur y nunca hacia el Norte. Se anota que desde 1928 en "Hombres pelearon" hay un enfrentamiento entre el Norte y el Sur, en este caso de "puñales".

Otro intertexto, aunque este de tipo filosófico, en la obra ensayística de Borges, es la presencia de las paradojas de Zenón de Elea:

\begin{abstract}
"Yo no tenía miedo, ni siquiera miedo de tener miedo, ni siquiera miedode tener miedo de tener miedo, a la infinita manera de los eleatas". (16),
\end{abstract}

En el ensayo "Avatares de la tortuga" Borges apuntó que

“...el vertiginoso regressus in infinitum es acaso aplicable a todos los temas... Al problema del conocimiento: conocer es reconocer, pero es preciso haber reconocido para reconocer, pero conocer es reconocer..." (17).

De este modo aplica un concepto filosófico para manifestar el narrador autodiegético sus sentimientos de "miedo" ante lo que le está sucediendo.

Borges ha reconocido su admiración por la obra del escritor latino Virgilio Publio Marón; ello explica la presencia de los dos textos intervirgilianos en los escritos de Borges, como es el caso de la cita textual que aparece en "Las hojas del ciprés" del verso veinticuatro de la "Bucólica Primera" y el cual reza de este modo.

"Quantum lenta solent inver viburns cupressi"

Del verso el narrador toma la palabra lenta y ofrece una explicación filológica al recordar que ella significa en el contexto virgiliano "flexible", lo cual resulta un contraste significativo con el sueño, ya que en él "las hojas del ciprés":

‘...nada tenían de flexibles" (18).

Si las "hojas" del poema de Virgilio pertenecen a la vida eglógica y por consiguiente, son hojas vivas, en cambio, las del texto borgense

"Eran iguales, rígidas y lustrosas y de materia muerta" (19). esto es, pertenecen a un mundo pesadillesco y constituyen la clave del relato presente ya en el título "Las hojas del ciprés".

Otro intertexto del poeta latino es el sintagma "Lento en la sombra" cuya deconstrucción en los textos de Borges es estudiada por Miguel d'Ors (20) y que en el caso presente es deconstruido así:

"Alto en la sombra" (21).

El "árbol de mi muerte" es un curioso intertexto de la mística española que identifica el árbol con la cruz. Recuérdese que al protagonista se le ordena tenderse en el pasto

“...de espaldas, con los brazos en cruz" (22),

al pie de un árbol, el que será luego definido como "El árbol de mi muerte era un ciprés" (23). La pluriacentuación de "árbol” en su código bucólico y en el de la tradición mística (24) se añade el significado horrible de los ajusticiamientos en campos abiertos y con la probabilidad de que ese crimen acontezca al pie de un árbol.

En cuanto a los intertextos históricos recuerdan éstos al lector la penosa y traumática experiencia que el pueblo argentino vivió en los años de 1976 a 1982, con motivo -entre otras cosas- de los secuestros de ciudadanos comunes, quienes en horas nocturnas eran hechos prisioneros en sus propios hogares. Muchos desaparecieron y por las tumbas comunes y clandestinas se supo que fueron condenados a muerte. En el relato, esta realidad histórica es vista como un sueño, a pesar de que el narrador ofrece una fecha precisa: "14 de abril de 1977". El despertar no significa incorporarse a la realidad histórica -Cfr. el diagrama de la página No.9, ya que el "enemigo" queda encerrado, al igual que el tomo de las obras Emerson, en la "pesadilla". La negación categórica de "Nunca regresará" (25) niega la historia, destacando sus horrores y vivirlos como si fuesen una pesadilla de la cual es imposible despertar, ya que se cae en otra nueva y así sucesivamente.

El protagonista de este "sueño" es un lector de Emerson, de la Biblia -sin ser creyente-, de las Mil y Una Noches, cuyos genios y hechiceros no hicieron nada para salvarlo del "enemigo"; también -como se 
vio- no sólo es conocedor de Virgilio sino que es latinista. También el "gato" es motivo de un poema llamado "Beppo" y éste tampoco hace nada por salvarlo de su "enemigo" (26).

El análisis que se ha planteado en este apartado sobre el tex to "Las hojas del ciprés" e igualmente, las relaciones establecidas de tal texto con el libro Los conjurados, muestran como tanto el uno como el otro constituyen la clausura de un trabajo de muchos años dedicados a un proyecto literario que se inició en 1933 con los textos que luego constituirían la obra Historia universal de la infamia. Cada uno de los puntos tocados en este análisis: diégesis, titulogía, el texto prefacial y los intertextos muestran a un productor consciente de su trabajo literario y quien acude a constantes claves y recursos, empleados en su narrativa inicial. También se colige, del estudio efectuado, que contrariamente a la decadencia señalada por algunos lectores de la obra de Borges a partir de 1970 (27), se da más bien, la culminación de un quehacer literario que simplifica los recursos estilísticos y cincela los nuevos textos, la jerga filosófica y las técnicas literarias de su producción, para retornar al carácter anecdótico de sus primigenios "ejercicios de prosa narrativa".

En resumen, los elementos esenciales del proyecto literario de Borges se mantienen en el texto "Las hojas del ciprés", revelando las claves de la génesis de su relato tal y como lo había utilizado el autor desde la fase liminar de su quehacer narrativo, es decir, en los textos integrantes del libro Historia universal de la infamia (28).

\section{NOTAS}

(1) Los conjurados, cuyo prólogo fue dictado por Borges en Ginebra el 9 de enero de 1985. Recuérdese que el escritor argentino murió el 14 de junio de 1986, precisamente en esa ciudad. Todo parece indicar que el libro antes citado fue la última obra de Borges. La obra consta de cuarenta textos: veintiséis poemas y catorce microrrelatos. Las citas que se dan en este artículo son tomadas de J.L. Borges Obras completas (Buenos Aires, EMECE, 1989) Vol.II; con el fin de abreviar se escribirá a la par de cada cita: O.C., vol.2, y el número de la página correspondiente.

(2) Pierre Macherey.

(3) Y (4) ambas citas

(5) Borges, O.C. vol 2, p.455.

(6) Ibidem, p.485.

(7) Ibidem.
(8) Ibidem, p.486.

(9) Ibidem.

(10) María Pérez Iglesias. "Ironía, dependencia y humor de la producción significante latinoamericana". Revista de Filología y Lingüística. Vol.9 (1) 1983, p.158.

(11) Este microrrelato forma parte del libro El oro de los tigres, publicado en 1972. Cfr. la cita hecha en Jorge L. Borges Obras Completas, [Vol.1] p.1132.

(12) Borges, O.C., vol. 2, p.485.

(13) Borges. Cfr. "El Sur" en su Obras completas, [vol.1], p.527.

(14) Borges, O.C., vol.2, p.485.

(15) Borges, O.C., vol.1, p.528.

(16) Borges, O.C., vol.2, p.485.

(17) Borges, "Avatares de la tortuga", ensayo que publicó en Discusión (1932). Cfr. sus Obras completas, [vol.1], p.258.

(18) Borges. O.C. vol.2, p.486.

(19) Ibidem.

(20) Este sintagma forma parte de un verso de la "Bucólica primera". El autor del artículo, Miguel d'Ors ubica las deconstrucciones de textos borgenses que van de Ficciones (1944) hasta La moneda de hierro (1976). Cfr. M. d'Ors "Sobre las construcciones del tipo 'lento en la sombra' en la obra de Jorge Luis Borges". Anales de Literatura Hispanoamericana. No. 5, 1976), pp.379-385.

(21) Borges, O.C. vol.2, p.485.

(22) Ibidem.

(23) Ibidem.

(24) Veánse las afirmaciones anteriores con el endecasílabo del poema "El pastorcico" escrito por San Juan de la Cruz, que dice: "sobre un árbol do abrió sus brazos bellos".

(25) Borges, O.C. vol.2, p.486.

(26) Cfr. Jorge Luis Borges en su poemario La cifra (1981), O.C. vol.2, p.297. Se sabe que este nombre correspondía al gato que en su apartamento tenía el escritor argentino.

(27) En este año edita Borges El informe de Brodie y en cuyo prólogo anuncia el nuevo rumbo de su producción narrativa, el que en verdad es un retorno a sus narraciones de Historia universal de la infamia.

(28) La consideración de apreciar Historia universal de la infamia como el incipit de la narrativa de Borges, se desprende de otros puntos investigados por el autor de este artículo, en su tesis Historia universal de la infamia: la subversión de un discurso narrativo. Univ. de C.R., S.E.P., 1988. 


\section{BIBLIOGRAFIA}

\section{A. SOBRE EL METODO}

Bajtin, Mijail M. Problemas de la poética de Dostoiesvski. Trad. de Tatiana Bubnova. México, Fondo de Cultura Económica, 1986.

Cros, Edmond. "Introducción a la sociocrítica". Káñina. Vol. X, (1986), No.1.

Chaverri, Amalia.Introducción a una titulología de la novelística costarricense. Tesis. Universidad de Costa Rica. Escuela de Filología, 1986.

Kristeva, Julia. El texto de la novela. Trad. de Jordi Llovet. 2a. edic., Barcelona, Lumen, 1981.

Macherey, Pierre. Pour une théorie de la production littéraire. Paris, Maspero, 1980.

Ortiz, María S. Concepción de l'identité latinoamericaine chez Alejo Charpentier: une lecture le recourse de la méthode. Tesis. Paris, Université de la Sorbonne Nouvelle, 1985.

Pérez Iglesias, María. "La semiología de la teoría de la productividad y la teoría del texto en Julia Kristeva". Revista de Filología y Lingüística. Vol. 7, (1981), Nos. 1 y 2.

"Ironía, dependencia y humor en la producción significante latinoamericana". Revistade Filología y Lingüística. Vol.9, (1983), No.1.

Peytard, Jean. "La place et la statut du 'lecteur' dans l'ensemble 'public' ". Semen, (1983), No.1.

Picard, Michel. "La lecture comme jeu". Poétique, Seuil (1984), No.58.

\section{B. DEL TEXTO}

Borges, Jorge Luis. Historia universal de la infamia. 9a. edic., Buenos Aires, EMECE, 1970

\section{OTRAS OBRAS DEL AUTOR}

Borges, Jorge Luis. Obras completas.. [Vol.1] Buenos Aires, EMECE, 1974.

. Obras completas. Vol.2. Buenos Aires, EMECE, 1989.

\section{CH. SOBRE EL AUTOR Y SU TEXTO}

Alazraki, Jaime. La prosa narrativa de Jorge Luis Borges. 3a. edic., Madrid, Gredos, 1983.

Alonso, Amado. "Borges narrador". Sur. (1935), No.105.

Carrizo, Antonio. Borges el momorioso (entrevista a...) México, Fondo de Cultura Económica, 1983. Colec. Tierra Firme.

Montanaro, Oscar. Historia universal de la infamia: la subversión de un discurso narrativo. Tesis, Universidad de Costa Rica, Sistema de Estudios de Posgrado, 1988.

Orgambide, Pedro. Borges y su pensamiento político. México, Comité de Solidaridad con el pueblo argentino, 1978.

Rodríguez Monegal, E.Jorge Luis Borges, ficcionario. Una antología de sus textos. Edición, introducción, prólogo y notas de Emir Rodríguez, México, Fondo de Cultura Económica, 1985. Colección Tierra Firme.

Viñas, David. De Sarmiento a Cortázar. 2a. edic. Buenos Aires, Siglo Veinte, 1974.

\section{SOBRE ASUNTOS ESPECIFICOS}

D’Ors, Miguel. "Sobre la construcción del tipo 'lento en la sombra' en la obra de Jorge Luis Borges". Anales de Literatura Hispanoamericana. (1976), No.5.

Fagg, John E. Historia general de Latinoamérica. Madrid, Taurus, 1970.

Vox.Diccionario general de la lengua española. 6 a. edic., Barcelona, Bibliograf, 1983. 